\title{
Impact of iron- and/or sulfate-reduction on a cis-1,2-dichloroethene and vinyl chloride respiring bacterial consortium: experiments and model-based interpretation
}

\author{
Murray, Alexandra Marie; Maillard, Julien; Rolle, Massimo; Broholm, Mette Martina; Holliger, Christof
}

Published in:

Journal of Environmental Monitoring

Link to article, DOI:

$10.1039 / \mathrm{c} 9 \mathrm{em} 00544 \mathrm{~g}$

Publication date:

2020

Document Version

Peer reviewed version

Link back to DTU Orbit

Citation (APA):

Murray, A. M., Maillard, J., Rolle, M., Broholm, M. M., \& Holliger, C. (2020). Impact of iron- and/or sulfatereduction on a cis-1,2-dichloroethene and vinyl chloride respiring bacterial consortium: experiments and modelbased interpretation. Journal of Environmental Monitoring, 22, 740-750. https://doi.org/10.1039/c9em00544g

\section{General rights}

Copyright and moral rights for the publications made accessible in the public portal are retained by the authors and/or other copyright owners and it is a condition of accessing publications that users recognise and abide by the legal requirements associated with these rights.

- Users may download and print one copy of any publication from the public portal for the purpose of private study or research.

- You may not further distribute the material or use it for any profit-making activity or commercial gain

- You may freely distribute the URL identifying the publication in the public portal 


\section{Accepted Manuscript}

This article can be cited before page numbers have been issued, to do this please use: A. Murray, J. Maillard, M. Rolle, M. Broholm and C. Holliger, Environ. Sci.: Processes Impacts, 2020, DOI:

\section{Environmental Science Processes \& Impacts}

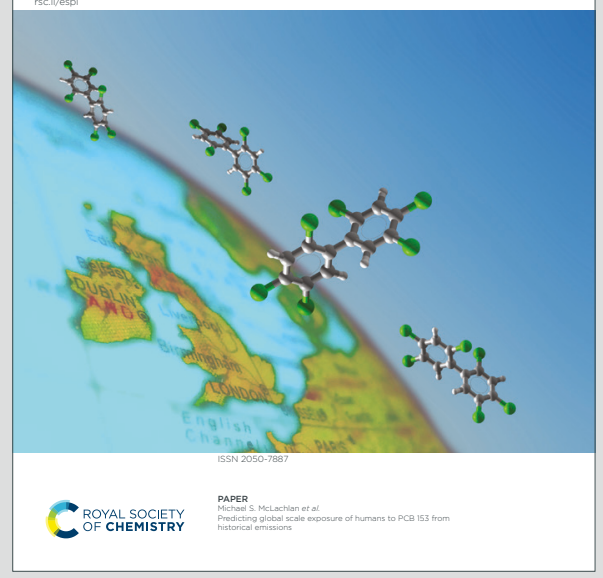

This is an Accepted Manuscript, which has been through the Royal Society of Chemistry peer review process and has been accepted for publication.

Accepted Manuscripts are published online shortly after acceptance, before technical editing, formatting and proof reading. Using this free service, authors can make their results available to the community, in citable form, before we publish the edited article. We will replace this Accepted Manuscript with the edited and formatted Advance Article as soon as it is available.

You can find more information about Accepted Manuscripts in the Information for Authors.

Please note that technical editing may introduce minor changes to the text and/or graphics, which may alter content. The journal's standard Terms \& Conditions and the Ethical guidelines still apply. In no event shall the Royal Society of Chemistry be held responsible for any errors or omissions in this Accepted Manuscript or any consequences arising from the use of any information it contains. 


\section{Impact of iron- and/or sulfate-reduction on a cis-1,2-dichloroethene and vinyl chloride}

2 respiring bacterial consortium: experiments and model-based interpretation

$4 \quad$ Alexandra Murray ${ }^{\mathrm{*}}$, Julien Maillard $^{\mathrm{b}}$, Massimo Rolle $^{\mathrm{a}}$, Mette Broholm ${ }^{\mathrm{a}}$, and Christof Holliger ${ }^{\mathrm{b}}$

5 aDepartment of Environmental Engineering, Technical University of Denmark, Kgs. Lyngby, DK-

62800, Denmark

7 bLaboratory for Environmental Biotechnology, ENAC-IIE, Ecole Polytechnique Fédérale de

8 Lausanne, 1015 Lausanne, Switzerland

$10{ }^{*}$ Corresponding author and address:

11 Alexandra Marie Murray

12 Department of Environmental Engineering,

13 Technical University of Denmark

14 Bld 115, 2800 Lyngby

15 Denmark

16 E-mail address: almu@env.dtu.dk,

17 Tel.: +4545252174 

51

\section{Keywords}

Degradation kinetics, microbial communities, biogeochemical modeling, organohalide respiration, chlorinated ethenes

\section{Environmental Significance}

Organohalide respiration is a natural environmental process that can be utilized for bioremediation of subsurface contaminants, e.g. chlorinated ethenes. This is a well-studied process, however the impacts of other subsurface microbial processes on organohalide respiration are much less well defined. This study was conducted in order to enhance understanding of the role of the microbial community on the rate of organohalide respiration, with specific emphasis on competing terminal electron accepting processes, namely sulfate and Fe(III) reduction. The different impacts from each sulfate-reducing and Fe(III)-reducing bacterial guild member on cis-1,2-dichloroethene and vinyl chloride dechlorination rates show that the dynamics within a microbial community containing organohalide-respiring bacteria cannot always be accurately characterized by broad, categorical, inter-guild trends, but are rather the result of intricate interactions between individual community members. This finding furthers understanding of how to best approach application of biodegradation of organic contaminants.

\section{Abstract}

Process understanding of microbial communities containing organohalide-respiring bacteria (OHRB) is important for effective bioremediation of chlorinated ethenes. The impact of iron and sulfate reduction on cis-1,2-dichloroethene (cDCE) and vinyl chloride (VC) dechlorination by a consortium containing the OHRB Dehalococcoides spp. was investigated using multiphase batch experiments. The OHRB consortium was found to contain endogenous iron- and sulfate-reducing 40 bacteria (FeRB and SRB). A biogeochemical model was developed and used to quantify the mass transfer, aquatic geochemical, and microbial processes that occurred in the multiphase batch 
system. It was determined that the added SRB had the most significant impact on contaminant

44 cDCE and VC by $129 \%$ and $294 \%$, respectively. The added FeRB had a slight stimulating effect on

45 VC dechlorination when exogenous SRB were absent, but when cultured with the added SRB,

46 FeRB moderated the SRB's stimulating effect. This study demonstrates that subsurface microbial

47 community interactions are more complex than categorical, guild-based competition for resources

48 such as electron donor. 

(n) (2)

\section{Introduction}

View Article Online

Chlorinated ethenes have been used at dry-cleaning facilities and in industry as metal degreasers for decades and are common groundwater contaminants. Naturally occurring organohalide-respiring bacteria (OHRB) can anaerobically degrade chlorinated ethenes by using them as electron acceptors paired often with hydrogen as an electron donor ${ }^{1}$. Sequential dechlorination of perchloroethene (PCE) and trichloroethene (TCE) yields the daughter products cis-1,2-dichloroethene (cDCE), vinyl chloride (VC), and ultimately the non-toxic ethene. PCE and all of its daughter products except ethene are toxic to humans, and thus it is advantageous to harness the capabilities of OHRB, both for natural attenuation and engineered bioremediation systems ${ }^{2}$. However, at many contaminated sites, sequential chlorinated ethene degradation inexplicably stops during one of the last two steps of the process: cDCE or $\mathrm{VC}$ accumulates, and the non-toxic endpoint is not achieved ${ }^{3}$.

The degradation stall can be due to a number of factors, including lack of specific functional genes in the OHRB or unfavorable environmental conditions, like low $\mathrm{pH}$ or lack of nutrients/vitamins ${ }^{4}$. Evidence from the laboratory, the field, and kinetic models suggests that, all other conditions being ideal, the degradation stall may be due to competition for electron donor in the groundwater microbial community (Fennell and Gossett, 1998). Hydrogen is produced by fermenting and syntrophic bacteria and can also be used in terminal electron accepting processes such as iron and sulfate reduction (Fennell and Gossett, 1998; Yang and McCarty, 1998). Previous studies support that iron- and sulfate-respiration directly impact organohalide-respiration (OHR) ${ }^{8,9}$, and competition for electron donor is often posited as the mechanism of impact. However, the extent of enhancement and/or inhibition by other reduction processes appears to be more complex than competition for electron donor, and can depend on the rates of hydrogen production and consumption ${ }^{10}$, sulfide concentration ${ }^{11}$, iron mineralogy ${ }^{12}$, and aqueous Fe(III) speciation ${ }^{13}$. 
73 Sulfate reduction has even been statistically correlated to increased chlorinated ethene degradation

74 in microcosm studies ${ }^{14}$.

75 Most kinetic OHRB laboratory studies are composed of carefully curated consortia, where only 76 those community members that support the OHRB growth are maintained, and do not include 77 quantification of these microbial community and geochemistry processes ${ }^{15-17}$. Geochemical 78 processes, such as the formation of iron complexes, have only been considered in a handful of 79 modeling efforts to describe community interactions, and these models have not been developed 80 based on dedicated experiment and modeling work ${ }^{9,18,19}$. Microbial activity in the subsurface is also 81 limited by mass transfer processes, such as kinetic dissolution of chlorinated ethenes from non82 aqueous phases ${ }^{20}$ and diffusive/dispersive processes, yet this is rarely included in lab-scale models 83 84 85

21,22. Therefore, exploration of the impact of sulfate- and iron-reducing bacteria (SRB and FeRB) on chlorinated ethene degradation by OHRB, while accounting for geochemical and mass transfer processes, is essential to further understanding of the interactions that occur within these microbial communities.

In this study, we conducted electron acceptor limited batch experiments that included a chlorinated ethene source and iron-sulfide geochemistry. We focused on cDCE and VC dechlorination in threephase batch systems, including a gas phase where hydrogen was supplied as electron donor, an organic liquid phase (hexadecane spiked with cDCE) acting as contaminant source, and an aqueous phase in which biodegradation and chemical reactions occurred. The relatively simple OHRB consortium was perturbed by the addition of other electron acceptors ( $\mathrm{Fe}(\mathrm{III})$ and sulfate) to the medium and FeRB and SRB to the inoculum, to form batch communities with different microbial guilds. We then interpreted the chemical and biomolecular experimental data using a kinetic biogeochemical model, whose foundational approach was developed in Murray et al., 2019. In contrast to Murray et al., 2019, the current study is conducted with the chlorinated ethenes cDCE 
and VC, rather than PCE, which are less reliably biodegradable in situ, is conducted over a span of

98 multiple months rather than a few days, and contains a more complex microbial community.

99 Furthermore, the model was significantly expanded to account for multiple dechlorination steps, utilize more types of data, and include sampling of multiple physical phases. This model which allowed us to accurately account for the fundamental physics of the batch systems in the current study, including mass transfer limitation between the different phases; quantify the rates of bacterial reduction processes; and distinguish the different physical, biological, and chemical processes that impact dechlorination of cDCE and VC by OHRB.

\section{Materials and methods}

\subsection{Microbial cultures}

The OHRB consortium, SL2, used in this study originated from a chlorinated ethene-contaminated aquifer and was enriched and maintained over several years ${ }^{23}$. The consortium contains the genus Dehalococcoides that is capable of sequentially respiring cDCE to VC and ethene. Shewanella oneidensis strain MR-1 ${ }^{24}$ was used as a model FeRB and Desulfovibrio vulgaris Hildenborough ${ }^{25}$ was used as a model SRB. S. oneidensis and D. vulgaris were selected because both can use hydrogen and neither can use acetate as an electron donor ${ }^{26-28}$. D. vulgaris is also capable of Fe(III) reduction, but does not grow when using this electron acceptor ${ }^{29,30}$.

\subsection{Experimental setup}

The base medium was prepared and sterilized in the same manner described in Murray et al. ${ }^{31}$. Acetate, ferric citrate, and sulfate stocks were each added such that in the finished medium approximately $2 \mathrm{mM}$ of carbon source, $5 \mathrm{mM}$ of iron source, and $5 \mathrm{mM}$ of sulfate source were present (Table S1). $60 \mathrm{~mL}$ of medium was added to each $125 \mathrm{~mL}$ batch bottle, and the headspace was replaced with a 4:1 mixture of hydrogen to carbon dioxide through $0.22 \mu \mathrm{m}$ sterile filters to a final pressure of 1.5 bar. Bottles were sealed with butyl rubber stoppers. An electron balance 
showed that $134 \%$ more donor was added to the system than was needed for all added electron acceptors. This excess of hydrogen was added directly to the system, rather than produced by fermenting populations in the microbial community, to ensure that all bacterial processes were electron acceptor limited. In the case that fermenting populations are present in the microbial community to produce hydrogen, this extra step in the process can serve to keep the hydrogen concentration low and thus electron donor limited ${ }^{6,32}$.

To avoid that the cells were exposed to toxic concentrations of cDCE, cDCE dissolved in hexadecane was used as a source in the system. Hexadecane is immiscible with water and remains as a distinct second liquid phase in the experimental batch system. The cDCE/hexadecane formed an organic layer between the aqueous and gaseous compartments in the bottle. As chlorinated ethenes are degraded in the aqueous phase, they diffuse from the organic layer to the gaseous and aqueous phases to maintain equilibrium at a non-toxic concentration in the aqueous phase. To avoid trace amounts of chloroform often present in commercially available cDCE, cDCE was produced in the laboratory using a Dehalobacter restrictus culture that degraded PCE to cDCE. When the PCE was exhausted and only cDCE remained, the organic layer was recovered from these cultures, diluted to approximately $200 \mathrm{mM}$ cDCE with hexadecane, and sterilized via autoclaving. An aliquot of $2 \mathrm{~mL}$ of the cDCE stock solution in hexadecane was added to each experimental batch, which created a thin (approximately $5 \mathrm{~mm}$ ) organic layer between the aqueous and gaseous phases. To ensure that the aqueous and gaseous phases did not intersect and that the only phase boundaries were the organic-aqueous and organic-gaseous boundaries, the batches were not agitated.

Aqueous samples of $1 \mathrm{~mL}$ were taken at regular intervals for chemical and molecular analyses. The sampling interval was three days for the first month of the experiment and one week for the remainder. Sampling continued for each experimental batch until dechlorination of all chlorinated 
ethenes was complete. Dechlorination was ascertained to be complete when chloride measurements produced the same value in consecutive sampling events.

SL2, S. oneidensis, and D. vulgaris were cultivated as separate inocula in a dark $30^{\circ} \mathrm{C}$ room. Cell counts were measured in each inoculum using universal qPCR. The same number of OHRB consortium cells were added to each experimental batch. The numbers of FeRB and SRB cells added were scaled to be 0.01 of the OHRB consortium cells. Four batch configurations were setup to investigate the OHRB activity and to explore the community interactions with the SRB and FeRB guilds. A schematic of the batch inocula configuration is included in Figure S1. Batch 1 consisted of the OHRB consortium alone, with neither FeRB nor SRB added. Batch 2 consisted of only the OHRB consortium and added SRB, Batch 3 consisted of only the OHRB consortium and added FeRB, and Batch 4 consisted of all three guilds together. All experimental batches were conducted in duplicate, statically, in a dark, $30^{\circ} \mathrm{C}$ room.

\subsection{Molecular methods}

Cell counts of each bacterial guild inoculum were quantified by quantitative polymerase chain reaction (qPCR) using universal primers $(\mathrm{SI})$ in order to inoculate each experimental batch with the appropriate inocula ratio. A MIC apparatus (Bio Molecular Systems) was used for analysis of the qPCR data. SRB and FeRB inocula were diluted with base medium prior to inoculation. PCR and terminal restriction fragment length polymorphism (T-RFLP) analyses were completed as described in the SI. Fragment counts of the modeled guilds (OHRB, SRB, indigenous SRB (SRBi), and FeRB) were selected and converted to cell counts based on the number of 16S rRNA gene copies per genome for each species ${ }^{24,25,33}$. These relative abundances based on cell number were then normalized to this selected portion of the community. Because fragments lengths of the indigenous FeRB (FeRBi) were identical to that of the exogenous FeRB, it was not possible to distinguish between these two populations using T-RFLP. Thus, the FeRBi and exogenous FeRB are modeled 
as one guild, and are referred to throughout this study as FeRB. Similarly, strains of OHRB could not be distinguished using the T-RFLP method (Berggren et al., 2013). Despite these limitations, the T-RFLP method was selected for use here to demonstrate the utility of a comparatively simple, cost-effective molecular method that can be applied to field and laboratory microbial community analyses.

\subsection{Analytical methods}

Total Fe(II) concentrations were assessed using a colorimetric ferrozine assay ${ }^{34}$. Samples were diluted ten times in $0.5 \mathrm{M} \mathrm{HCl}$ directly upon removal to prevent oxidation of iron(II) to iron(III) ${ }^{35}$ and were analyzed immediately. Chloride concentrations were assessed via silver ion titration with a Chlor-o-counter (Flohr Instument, Nieuwegein, Netherlands). Sulfate concentrations were measured by ion chromatography - suppressed conductivity detection (ICS-5000, Thermo Fisher). Samples were pretreated with a cleanup-cartridge ( 1 cc, Dionex OnGurad II Na, ThermoScientific) to remove divalent metal ions, which protects the column and suppressor. Samples were diluted five times in a 5\% zinc acetate solution directly upon removal to trap sulfide as zinc sulfide and were frozen at $-20^{\circ} \mathrm{C}$ until analysis. A sample of $1 \mathrm{~mL}$ was taken from each batch to measure $\mathrm{pH}$ prior to inoculation and at the end of the time series to ensure that the medium remained buffered at $\mathrm{pH} 7$ throughout the experimental duration. The gas composition in each batch headspace was measured by gas chromatography (Agilent Technologies 7890B system equipped with Optima 624 LB) ${ }^{36}$. Peak areas were corrected using the molar mass of each compound and are representative of the relative headspace composition. The proportions of $\mathrm{cDCE}, \mathrm{VC}$, and ethene were normalized as relative proportions of these three compounds.

\subsection{Biogeochemical model}

The modeling tool used to interpret the batch experiments is founded on an approach that couples MATLAB $^{\circledR}$ and the geochemical code PHREEQC ${ }^{37}$ via the IPhreeqc module ${ }^{38,39}$. A detailed 
A set of differential equations is used to describe the transfer of moles of $\mathrm{cDCE}, \mathrm{VC}$, ethene and hydrogen between the gaseous, organic, and aqueous phases, represented by the slim black arrows on the conceptual schematic in Figure 1 (Equations S1-S5). Dual Monod kinetics (Equation S6) are used to describe chlorinated ethene respiration by OHRB (thick black arrows, Figure 1), sulfate reduction by SRB and SRBi (green and dark yellow arrows, respectively, Figure 1) and Fe(III) reduction by FeRB (red arrows, Figure 1). First order kinetics are used to model Fe(III) reduction by SRB and SRBi (green and dark yellow arrows, respectively, Figure 1, Equation S8) ${ }^{29}$, and speciation reactions (Table S2) were used to determine the bioavailable portion of Fe(III)-citrate ${ }^{40}$. Hydrogen is consumed in all bacterial processes (blue lines, Figure 1). Abiotic Fe(III) reduction by biogenic sulfide (Equation S9-S10) is included in the model to proceed as first order with respect to $\mathrm{Fe}(\mathrm{III})$ and 0.5 order with respect to sulfide (dotted black lines, Figure 1) ${ }^{41}$. Precipitation of Fe(II) 
and sulfide as amorphous mackinawite (Equation S11) is included as an equilibrium reaction in the

216 PHREEQC reaction module (dotted black lines, Figure 1) ${ }^{42}$. Chemical reactions included in the

9217 model are listed in Table 1. Expressions for mass transfer, aqueous speciation, biotic Fe(III) and 10

11218 sulfate reduction, bacterial growth and decay, abiotic $\mathrm{Fe}(\mathrm{III})$ reduction, and $\mathrm{FeS}_{(\mathrm{s})}$ precipitate formation are included in the SI (Equations S1-S11).

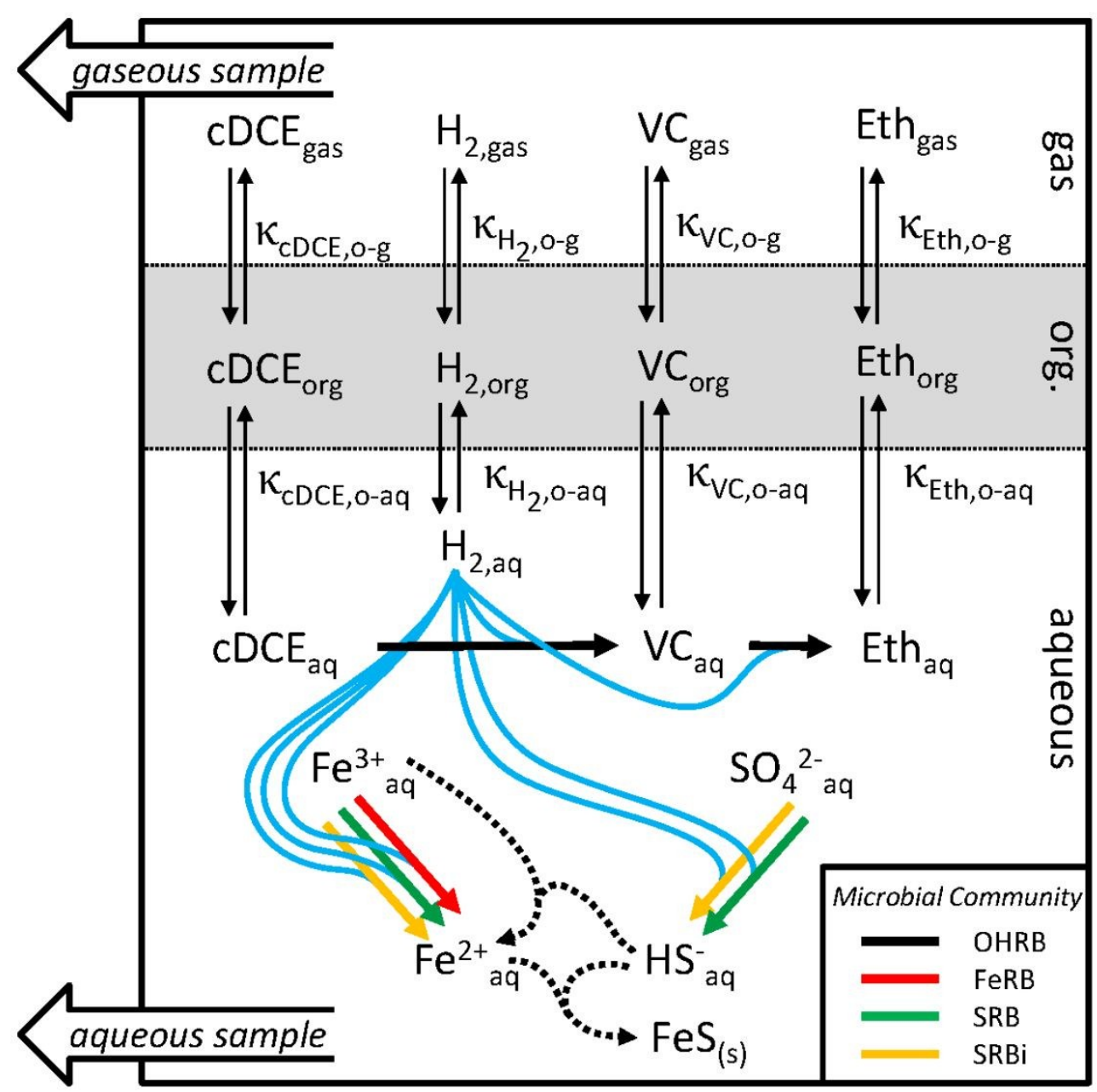

Figure 1. Conceptual model of the processes that occur in the experiment. Slim, black arrows:

mass transfer processes; $\kappa_{i, o-a q}$ is the mass transfer coefficient between the organic and aqueous phases, and $\kappa_{i, o-g}$ between the organic and gas phases, for compound $i$. Thick arrows indicate microbial processes: black: chlorinated ethene dechlorination by OHRB, red: iron 
reduction by FeRB (both added FeRB and FeRB native to the OHRB consortium), and dark green and dark yellow: sulfate and iron reduction by added SRB and SRBi (SRB native to the

OHRB consortium), respectively. Blue lines: hydrogen used in these reduction processes.

Dotted black lines: abiotic geochemical processes. Note that Fe(II) and Fe(III) speciation is not

Table 1. Stoichiometry of biogeochemical reactions included in the model. $R_{E D}=$ electron

explicitly included in the conceptual model.

donor half-reaction, $R_{E A}=$ electron acceptor half reaction, $R_{B i o}=$ biomass synthesis half

reaction. See SI for kinetic description of $R_{E A}: F e^{3+}$ for SRB and SRBi, $R_{A b i o}: F e^{3+}$, and $R_{\text {precip: }}$

$\mathrm{FeS}_{(s)}$

\begin{tabular}{|c|c|c|}
\hline Reaction & Group & Stoichiometry \\
\hline $\mathrm{R}_{\mathrm{ED}}$ & OHRB, FeRB, SRB, SRBi & $\frac{1}{2} H_{2} \rightarrow H^{+}+e^{-}$ \\
\hline $\mathrm{R}_{\text {Bio }}$ & OHRB, FeRB, SRB, SRBi & $\frac{1}{2} \mathrm{CH}_{3} \mathrm{COO}^{-}+\frac{1}{4} \mathrm{CO}_{2}+\frac{1}{4} \mathrm{NH}_{4}^{+}+\frac{5}{4} \mathrm{H}^{+}+e^{-} \rightarrow \frac{1}{4} \mathrm{C}_{5} \mathrm{H}_{7} \mathrm{O}_{2} \mathrm{~N}+\mathrm{H}_{2} \mathrm{O}$ \\
\hline $\mathrm{R}_{\mathrm{EA}}: \mathrm{cDCE}$ & OHRB & $\frac{1}{2} \mathrm{C}_{2} \mathrm{H}_{2} \mathrm{Cl}_{2}+\mathrm{H}^{+}+e^{-} \rightarrow \frac{1}{2} \mathrm{C}_{2} \mathrm{H}_{3} \mathrm{Cl}+\frac{1}{2} \mathrm{H}^{+}+\frac{1}{2} \mathrm{Cl}^{-}$ \\
\hline $\mathrm{R}_{\mathrm{EA}}: \mathrm{VC}$ & OHRB & $\frac{1}{2} \mathrm{C}_{2} \mathrm{H}_{3} \mathrm{Cl}+\mathrm{H}^{+}+e^{-} \rightarrow \frac{1}{2} \mathrm{C}_{2} \mathrm{H}_{4}+\frac{1}{2} \mathrm{H}^{+}+\frac{1}{2} \mathrm{Cl}^{-}$ \\
\hline $\mathrm{R}_{\mathrm{EA}}: F e^{3+}$ & FeRB, SRB, SRBi & $F e^{3+}+e^{-} \rightarrow F e^{2+}$ \\
\hline $\mathrm{R}_{\mathrm{EA}}: S O_{4}^{2-}$ & $\mathrm{SRB}, \mathrm{SRBi}$ & $\frac{1}{8} \mathrm{SO}_{4}^{2-}+\frac{19}{16} \mathrm{H}^{+}+e^{-} \rightarrow \frac{1}{16} \mathrm{H}_{2} S_{(g)}+\frac{1}{16} \mathrm{HS}^{-}+\frac{1}{2} \mathrm{H}_{2} \mathrm{O}$ \\
\hline $\mathrm{R}_{\mathrm{Abio}}: F e^{3+}$ & Abiotic & $2 \mathrm{Fe}^{3+}+H S^{-} \rightarrow 2 \mathrm{Fe}^{2+}+S^{0}+H^{+}$ \\
\hline $\begin{array}{l}\mathrm{R}_{\text {precip }}: \\
\quad F e S_{(s)}\end{array}$ & Abiotic & $\mathrm{Fe}^{2+}+\mathrm{HS}^{-} \rightarrow \mathrm{FeS}_{(s)}+\mathrm{H}^{+}$ \\
\hline
\end{tabular}

Dechlorination of cDCE to ethene was modelled as a two-step process, with production and consumption of the intermediate VC. Competitive inhibition by $\mathrm{cDCE}$ reduction was included in 
where $d C_{V C, a q} / d t$ [mol L-1 $\left.\mathrm{h}^{-1}\right]$ is the temporal change in the VC concentration in the aqueous phase;

$C_{c D C E, a q}, C_{V C, a q}$, and $C_{H 2, a q}[\mathrm{M}]$ are the aqueous concentrations of cDCE, VC, and hydrogen; $k_{\max , C D C E}$ and $k_{\max , V C}\left[\mathrm{~mol}\right.$ cell $\left.^{-1} \mathrm{~s}^{-1}\right]$ are the maximum specific reduction rates of $\mathrm{CDCE}$ and $\mathrm{VC} ; X$ [cells $\left.\mathrm{L}^{-1}\right]$ is the biomass concentration; $t[\mathrm{~s}]$ is time; $K_{S, c D C E}, K_{S, V C}$, and $K_{S, H 2}[\mathrm{M}]$ are the halfsaturation constants for $\mathrm{CDCE}, \mathrm{VC}$, and hydrogen; and $K_{C I, c D C E}[\mathrm{M}]$ is the competitive inhibition coefficient. As described in ${ }^{17}, K_{C I, c D C E}$ is equivalent to $K_{S, c D C E}$. Similarly to Murray et al., 201931, the maximum specific reduction rates of the bacterial guilds were fitted for during model development. Simple manual calibration of the key kinetic parameters to the experimental observations was performed in this study. The normalized root mean square error (NRMSE) was minimized to obtain the best fit. The function $L(t)$ (Equation 2) describes the lag-time for each batch $40,43,44$ :

$$
L(t)=\left[\begin{array}{ll}
=0 & t \leq t_{\text {lag }} \\
=1 & t>t_{\text {lag }}
\end{array}\right.
$$


where the $t_{\text {lag }}[\mathrm{s}]$ is the time from the start of the batch until the lag time ends and the exponential growth phase begins. The lag function was used to simulate the processes carried out by the OHRB and SRBi guilds, and was not needed for the SRB and FeRB guilds.

The mass transfer of the volatile compounds cDCE, VC, ethene, and hydrogen across the organicgaseous and organic-aqueous phase boundaries and the evolution of their amounts in the different phases were modeled by:

$$
\left(\frac{d n_{i}}{d t}\right)_{o r g-j}=V_{j}\left(C_{i, j}^{e q}-C_{i, j}\right)\left(\frac{\kappa_{i, o r g-j} A}{V_{\text {org }}}\right)
$$

where $\left(d n_{i} / d t\right)_{\text {org-j } j}\left[\mathrm{~mol} \mathrm{~s}^{-1}\right]$ is the change in moles of compound $i$ through time, $t[\mathrm{~s}]$, across the boundary between the organic phase and phase $j, V_{j}[\mathrm{~L}]$ is the volume of phase $j, C_{i, j}[\mathrm{M}]$ and $C^{e q} q_{i, j}$ $[\mathrm{M}]$ are the concentration and equilibrium concentration of compound $i$ in phase $j, \kappa_{i, \text { org-j }}\left[\mathrm{dm} \mathrm{s}^{-1}\right]$ is the mass transfer coefficient, and $A\left[\mathrm{dm}^{2}\right]$ is the cross-sectional area of the phase interface ${ }^{21}$.

Gas and aqueous phase samples were collected in this experiment. The modeling approach accounts for the removal of mass from the aqueous phase and the gaseous headspace by:

$$
\begin{gathered}
n_{i}=C_{i, g a s} V_{g a s}+C_{i, o r g} V_{\text {org }}+C_{i, a q} V_{a q}-C_{i, a q} V_{S, a q} \\
n_{i}=C_{i, g a s} V_{g a s}+C_{i, a q} V_{a q}+C_{i, o r g} V_{o r g}-\left(\frac{C_{i, g a s} V_{\text {gas }}}{V_{\text {gas }}+V_{S, \text { gas }}}\right) V_{S, \text { gas }}
\end{gathered}
$$

where $n_{i}$ [mole] is the remaining moles of compound $i$ after the sample is removed, $C_{i, j}[\mathrm{M}]$ is the concentration of compound $i$ in phase $j, V_{j}[\mathrm{~L}]$ is the volume of phase $j$, and $V_{S, a q}$ and $V_{S, \text { gas }}[\mathrm{L}]$ is the volume of the removed sample. The volume of the headspace does not change when a gas sample is collected; $V_{S, g a s}$ can most accurately be described as the volume by which the headspace increases before the sampling syringe is removed. The concentrations of the compound in each phase after 
sample removal was then calculated ${ }^{45}$ using the partition coefficients $K_{\text {gas-org }}$ and $K_{\text {org-aq }}$ [-] (Table

View Article Online 6 9270 phase.

S3) and the pressure calculated based on the change in moles of volatile compounds in the gas

\section{Results}

The OHRB consortium was naturally capable of iron- and sulfate-reduction. These processes were promoted by the addition of $\mathrm{Fe}(\mathrm{III})$ and sulfate to the growth medium. Each batch experiment therefore did not differ in the processes present in the batch system but by the rate of those processes and the changes in the microbial community composition. We collected aqueous and gaseous samples and analyzed for chlorinated ethenes, chloride, Fe(II), sulfate, and community composition. First we present the changes in sulfate concentration and microbial community, then the multiple complementary datasets and the model simulations, and lastly we describe and discuss the impact of the community composition on the $\mathrm{cDCE}$ and $\mathrm{VC}$ respiration kinetics. 


\subsection{Sulfate-reducing Desulfovibrio populations}

281 A decrease in the sulfate concentration through time was observed in all batches, including those

where no SRB was added (Figure 2). There are clear similarities in Batches 1 and 3, where SRB were not expressly added via the batch inoculum, versus Batches 2 and 4, where SRB were expressly included in the batch inoculum. In Batches 1 and 3, the sulfate concentration decreased slowly in the first 6 days, decreased more rapidly from day 6 , and all sulfate was consumed by day 16. In Batches 2 and 4, the sulfate concentration began to decline between days 0 and 3 and all sulfate was consumed within the first 9 days of the experiment. The disappearance of sulfate coincides with visual observation of black, iron-sulfide precipitate formation in each batch.
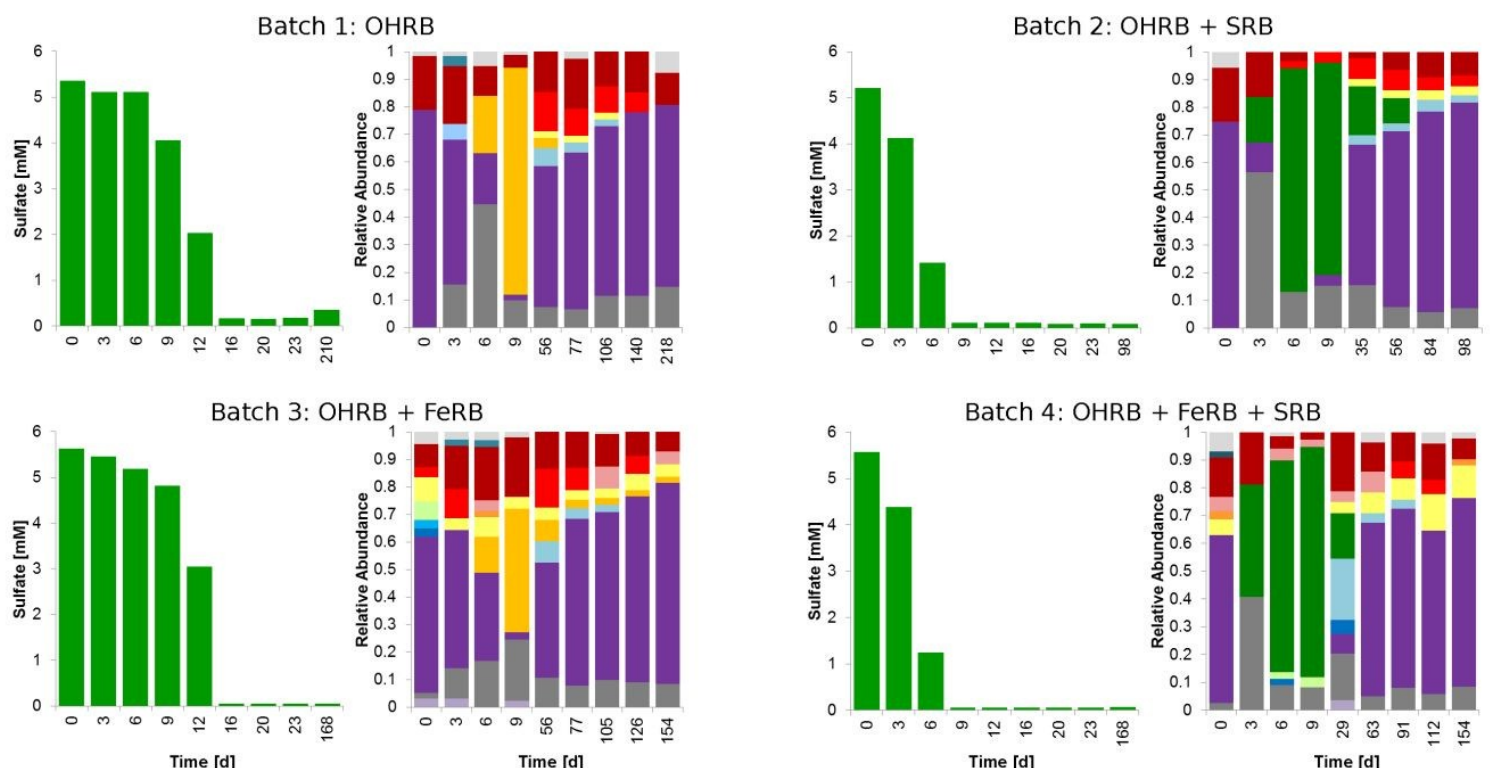

$+\mathrm{FeRB}+\mathrm{SRB}$$$
\text { Time [d] }
$$

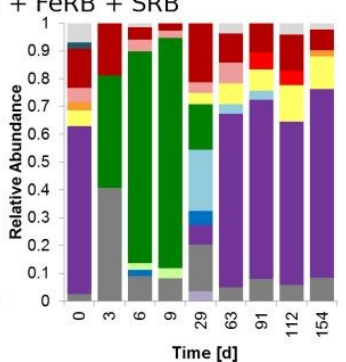

$$
=66 \text {. }
$$

208-210

Figure 2. Sulfate concentration and relative abundance for all experimental batches. Color legend indicates fragment lengths identified through T-RFLP analysis. Fragments of length 126-128: Dehalococcoides spp. (OHRB), 205-206: exogenous Desulfovibrio vulgaris (SRB), 208-210: endogenous Desulfovibrio spp. (SRBi), 234: exogenous and endogenous Shewanella oneidensis (FeRB). All other terminal fragments with other lengths indicate other populations 
present in the microbial community (see SI for more details). Note that the time scale on the

$x$-axis has been selected to show observed trends in the data and is not consistent between

\section{panels. Original batch data is presented; original and duplicate batch data are presented in}

\section{Figure S2.}

In all experimental batches, T-RFLP shows that fragments attributed to Dehalococcoides spp.

comprise between $60-80 \%$ of the total fragments present in the microbial community at the

beginning of the experiment. As sulfate concentrations decrease, these OHRB fragments decrease in relative abundance and fragments of length 205-206 (Batches 2 and 4) and length 208-210 (Batches 1 and 3) increase in relative abundance. Fragments of length 205-206 were attributed to the endogenous Desulfovibrio spp. and fragments of length 208-210 were attributed to the added SRB, Desulfovibrio vulgaris Hildenborough (see SI). Based on the correlation between the sulfate concentration decrease and the observed shifts in relative abundance, these Desulfovibrio populations are likely responsible for sulfate reduction. While SRB were not added to Batches 1 and 3 , it is assumed that the addition of sulfate to the medium stimulated sulfate reduction in a Desulfovibrio population indigenous to the OHRB consortium (the aforementioned SRBi). Both populations reduced sulfate in a period of approximately 10 days, but the SRBi appear to have experienced a lag period at the beginning of the time series. This lag phase renders the SRBi unable to establish a population large enough to be identified through T-RFLP analysis when the exogenous SRB are added. The SRB and SRBi decrease in relative abundance once sulfate is depleted, when the OHRB increase in relative abundance to once again dominate the microbial community.

Fragments of length 234, attributable to Shewanella oneidensis, the added FeRB, were also found in 55316 56 
consortium (see SI), and exogenous and endogenous populations in Batches 3 and 4 could not be

distinguished using T-RFLP. It is also of note that there is excellent agreement between the

duplicates for each batch, in both sulfate concentration and microbial community composition (Figure S2).

\subsection{Physical and biogeochemical data and process simulations}

The multiple, complementary datasets gathered for each of the experimental batches and their simulated development through time are depicted in Figure 3 (example for Batch 3, all batches and duplicates in SI, all NRMSE values in SI). All batches and their duplicates demonstrate a relatively slight increase in the chloride concentration (Figure 3a) within the first 9 days of the experiment, which is speculated to be the result of residual activity in the inoculum. The measured chloride concentration then plateaued for a period of approximately one month before increased concentrations of this OHR product were detected. After the plateau, the chloride concentration increased rapidly for a period of approximately three weeks and then increased less rapidly for the remainder of the experiment. It appears that the change in behavior of the aqueous chloride concentration increase aligns with the disappearance of $\mathrm{cDCE}$ and appearance of ethene in the headspace (Figure 3a and Figure 3d). Sulfate and Fe(II) concentrations (Figure 3c) showed exhaustion of the electron acceptors sulfate and Fe(III) within the first two weeks of each experimental duration. The evolution of these aqueous chemical parameters were captured fairly well in the case of Fe(II) and very well in the case of chloride and sulfate. Abiotic reduction and mineral precipitation reactions in the model simulations in this study are discussed in detail in Murray et al., 201931. Lastly, it is important to note that the x-axis in Figure 3c is scaled differently than the other panels; all sulfate and Fe(III) in all batches was reduced before chloride appreciation began. 
(a)

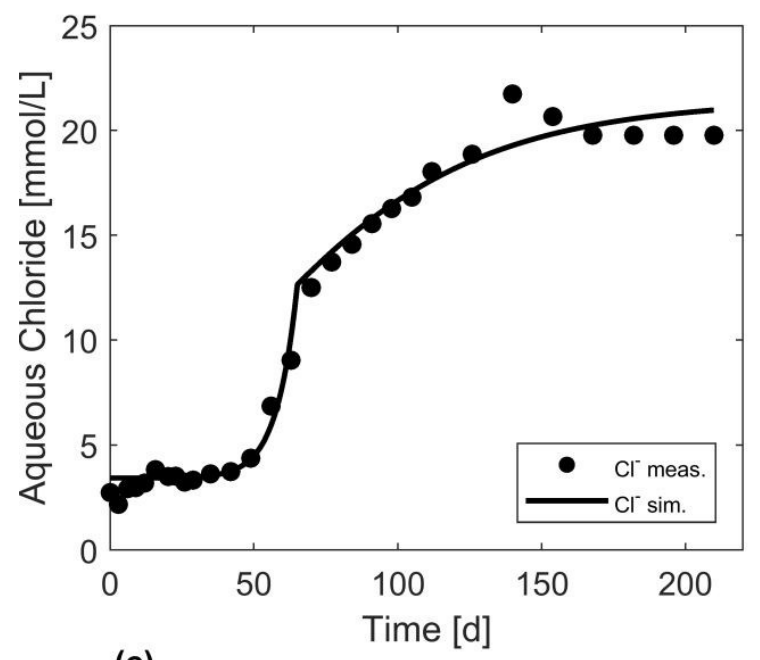

(c)

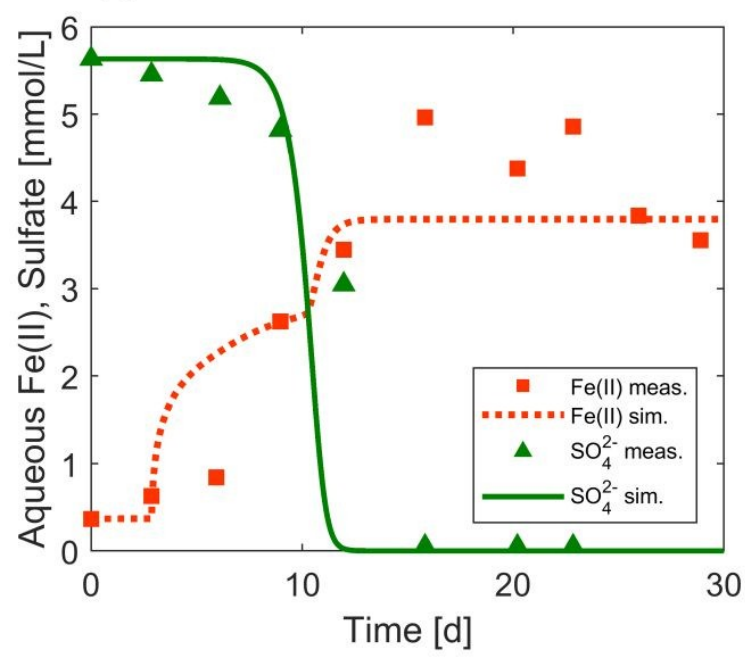

(b)

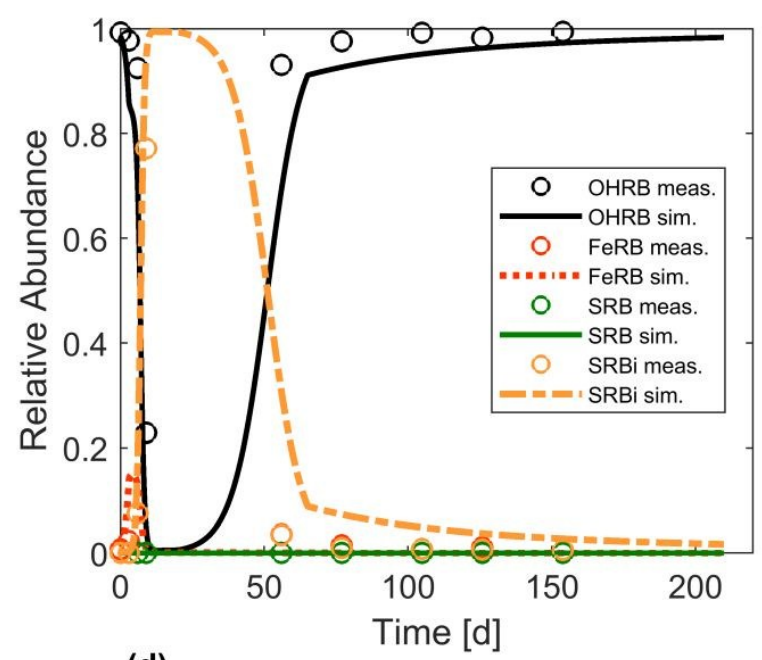

(d)

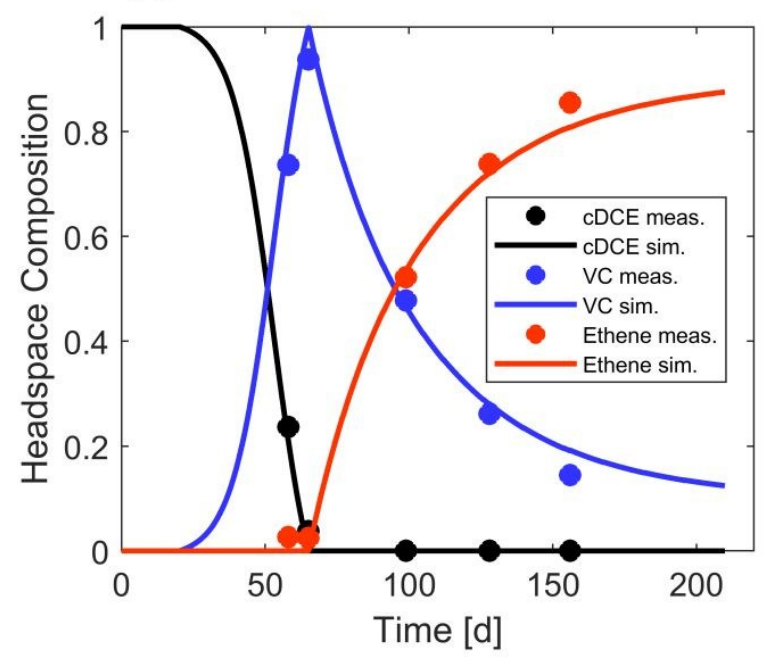

Figure 3. Data and simulations for aqueous chloride concentration (a), microbial population relative abundance (b), aqueous total Fe(II) and sulfate concentrations(c), and relative headspace composition of chlorinated ethenes (d). Example shown for Batch 3 (OHRB, FeRB, and SRBi), other batches and all batch duplicates in SI (Figures S3-S8). Relative abundance (b) data are normalized to the four selected guilds $O H R B, F e R B, S R B$, and SRBi. Time axis is scaled for panel (c) to best display the change in concentration that occurs at the beginning of the time series. 
Normalized relative microbial community abundance data (Figure $3 \mathrm{~b}$ ) depict the same trend seen in Figure 2; the dominant population shifts from OHRB at the beginning of the experiment to SRB or $\mathrm{SRBi}$, and then shifts back to OHRB after approximately 1.5 months. The model is able to simulate these shifts in dominance, both for SRBi (Figure 3b) and for SRB (SI). Measurement of the relative headspace composition (Figure 3d) shows that nearly all cDCE is transformed to VC, which is further transformed to ethene. The abrupt disappearance of $\mathrm{cDCE}$ in the headspace and the gradual transformation of VC to ethene suggest that competitive inhibition is only present in one direction (i.e. cDCE inhibits VC dechlorination) ${ }^{18}$. Simulations using this one-way competitive inhibition successfully capture the transitions from cDCE to VC and from VC to ethene.

The example of the multiple datasets and simulations for Batch 3 presented in Figure 3 demonstrates that the processes occurring in the experimental batch system are accurately described by the proposed model. Successful simulation of both the aqueous chemical species and the microbial community relative abundance show quantitative understanding of how the reduction processes, aquatic geochemistry, and bacterial growth are linked. Likewise, simulation of the chloride concentration and the relative headspace evolution demonstrate understanding of how chloride production is attributed to each step in the two-step dechlorination process. Additionally, capturing the dynamic changes in the headspace composition demonstrates that the model is able to accurately capture mass transfer in the multiphase system.

\subsection{Microbial process comparison and dechlorination kinetics}

Because the concentration of the intermediate VC was established, the contribution of each chlorinated ethene degradation step to the aqueous chloride measured concentration could be distinguished. The evolution of chlorinated ethene degradation in the batches can then be inferred from the chloride concentration evolution. When comparing the chloride concentrations of each batch (Figure 4), there appears to be a difference in the duration of the concentration plateau, 
hereafter called the OHR lag phase, between Batches 1 and 3 and Batches 2 and 4. However,

differences in the lag duration between duplicates in Batches 3 and 4 (SI) indicate this is unlikely

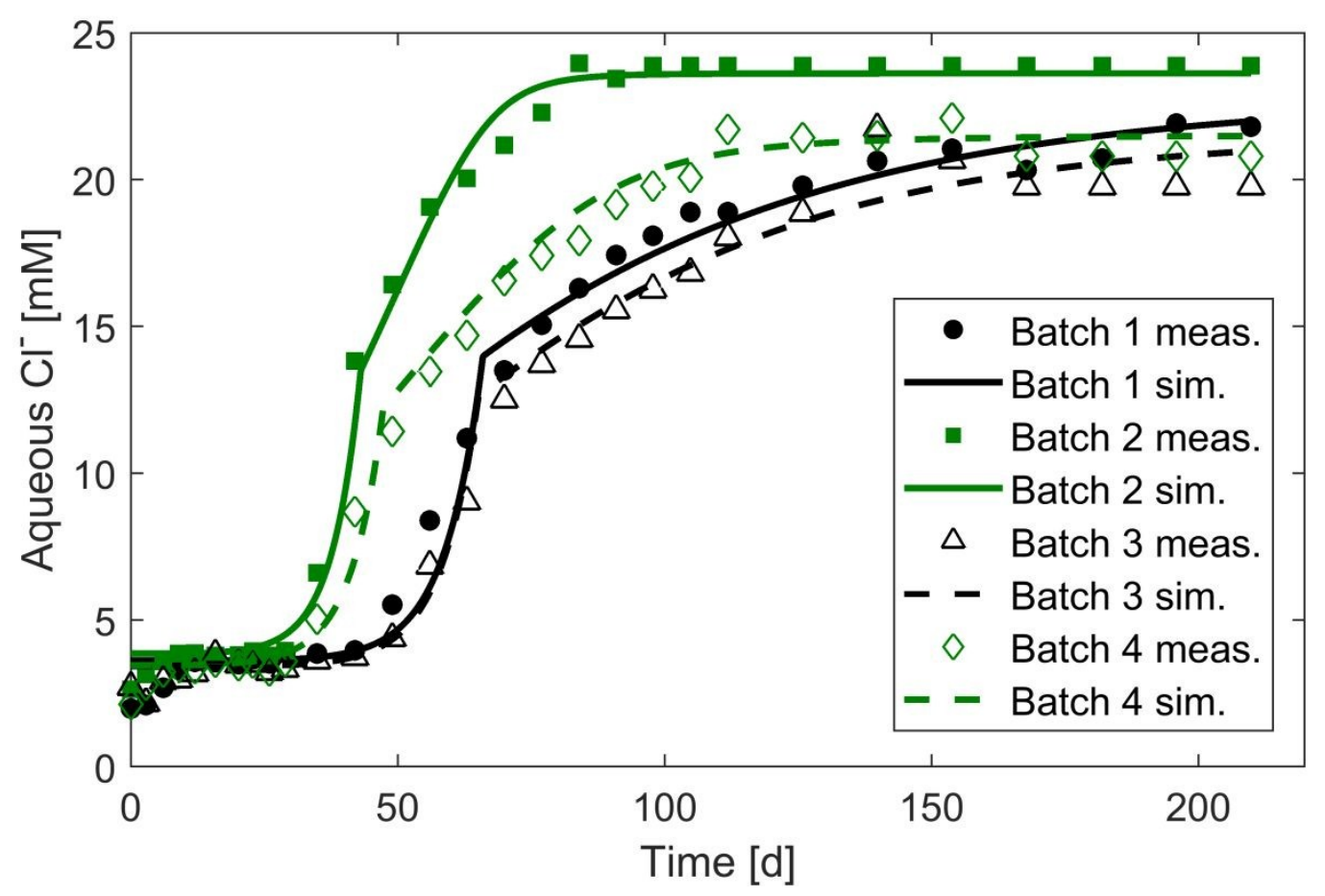

Figure 4. Chloride evolution data (points) and simulations (lines) for all batches. Filled data points and solid lines represent batches without exogenous FeRB (Batch 1 \& 2); open data points and dashed lines represent batches with exogenous FeRB (Batch 3\&4). Black data points and lines represent batches without exogenous SRB (Batch 1\&3); green data points and lines represent batches with exogenous SRB (Batch 2\&4).

Particularly in the later parts of the curve, the observed increase in the measured chloride concentration was more rapid in Batches 2 and 4, those with exogenous SRB, than in Batches 1 and 3 (Figure 4). In the later points during the time series, $\mathrm{cDCE}$ is depleted and all produced chloride 

is attributable to VC respiration. The shift from the period where $\mathrm{CDCE}$ dechlorination dominates to where VC dechlorination dominates is apparent by a shift in the slope of each simulated chloride curve (Figure 4).

Each batch and its duplicate were simulated using the same electron acceptor maximum specific utilization rates $k_{\max , c D C E}$ and $k_{\max , V C}$ (Table 2, Figure S3), affirming that when the lag phase is accounted for, there is agreement between the duplicates. By including a lag period of $3 \mathrm{~d}$ for SRBi, both SRB guilds were able to be fit using the same $k_{\max , S R B}, K_{S, S R B, S O 4}$, and $K_{S, S R B, H 2}$ (Table 2, Table S2). Similarly, the endogenous and exogenous FeRB were able to be simulated by the same set of $k_{\max , F e R B}, K_{S, F e R B, F e 3}$, and $K_{S, F e R B, H 2}$ kinetic parameters (Table 2, Table S2).

Table 2. Maximum specific substrate utilization rates determined for each batch and its duplicate

\begin{tabular}{|c|c|c|c|c|c|}
\hline Batch & Inoculum & $\begin{array}{c}\boldsymbol{k}_{\max , \boldsymbol{c D C E}} \\
\mathrm{mol}_{\mathrm{CDCE}} \text { cell }^{-1} \mathrm{~s}^{-1}\end{array}$ & $\begin{array}{c}\boldsymbol{k}_{\max , V C}, \boldsymbol{V} \\
\mathrm{mol}_{\mathrm{VC}} \text { cell }^{-1} \mathrm{~s}^{-1} \\
\end{array}$ & $\begin{array}{c}\boldsymbol{k}_{\max , \boldsymbol{F e R B}} \\
\mathrm{mol}_{\mathrm{Fe} 3} \mathrm{cell}^{-1} \mathrm{~s}^{-1} \\
\end{array}$ & $\begin{array}{c}\boldsymbol{k}_{\text {max }, \boldsymbol{S R B}} \\
\text { mol }_{\mathrm{SO} 4} \operatorname{cell}^{-1} \mathrm{~s}^{-1} \\
\end{array}$ \\
\hline 1 & OHRB & $7 \times 10^{-20}$ & $8.5 \times 10^{-21}$ & \multirow{4}{*}{$1 \times 10^{-18}$} & \multirow{4}{*}{$7 \times 10^{-18}$} \\
\hline 2 & $\mathrm{OHRB}+\mathrm{SRB}$ & $9 \times 10^{-20}$ & $2.5 \times 10^{-20}$ & & \\
\hline 3 & $\mathrm{OHRB}+\mathrm{FeRB}$ & $7 \times 10^{-20}$ & $1.0 \times 10^{-20}$ & & \\
\hline 4 & $\mathrm{OHRB}+\mathrm{SRB}+\mathrm{FeRB}$ & $8 \times 10^{-20}$ & $1.6 \times 10^{-20}$ & & \\
\hline
\end{tabular}

Batches 1 and 3 were simulated by the same cDCE dechlorination rate, which was also the slowest of all four batches. The $k_{\max , c D C E}$ for Batches 2 and 4, which included the exogenous SRB, were $129 \%$ and $114 \%$ higher, respectively, than in Batches 1 and 3. The $k_{m a x, V C}$ varied for each batch, and was slowest in Batch 1 . The $k_{\max , V C}$ for Batches 2,3 , and 4 were $294 \%, 118 \%$, and $188 \%$ higher, respectively, than for Batch 1 . The two highest $k_{\max , c D C E}$ and $k_{\max , V C}$ were found for Batches 2 and 4, which included the exogenous SRB. Model simulations also show that aqueous hydrogen concentrations never decreased below $9.7 \times 10^{-5} \mathrm{M}$, confirming that the systems were indeed electron acceptor limited. 
Simulation results for the biotic consumption of electron acceptors in Figure 5 show how the microbial processes occurred at different times during the experimental duration. The same maximum Fe(III) and sulfate utilization rates for the FeRB and SRB/SRBi, respectively, were able to capture the behavior of these guilds, and the extent of these processes then impacted cDCE and VC dechlorination, which occurred later in the time series. The maximum consumption rate for the OHRB processes is much lower than that of the SRB and FeRB processes, and the duration of these OHRB processes is much longer. The abrupt decrease in the cDCE and increase in VC dechlorination rates is due to the choice to model the system as inhibited in one direction. The inclusion of exogenous SRB and subsequent increase in the $k_{\max , V C}$ impacts the shape of the VC dechlorination rate curve. In Batches 2 and 4, which included the exogenous SRB, the VC consumption rate is sustained at a higher level for a period of time, whereas in Batches 1 and 3, without the exogenous SRB, the VC rate steadily decreases until the end of the experiment. 

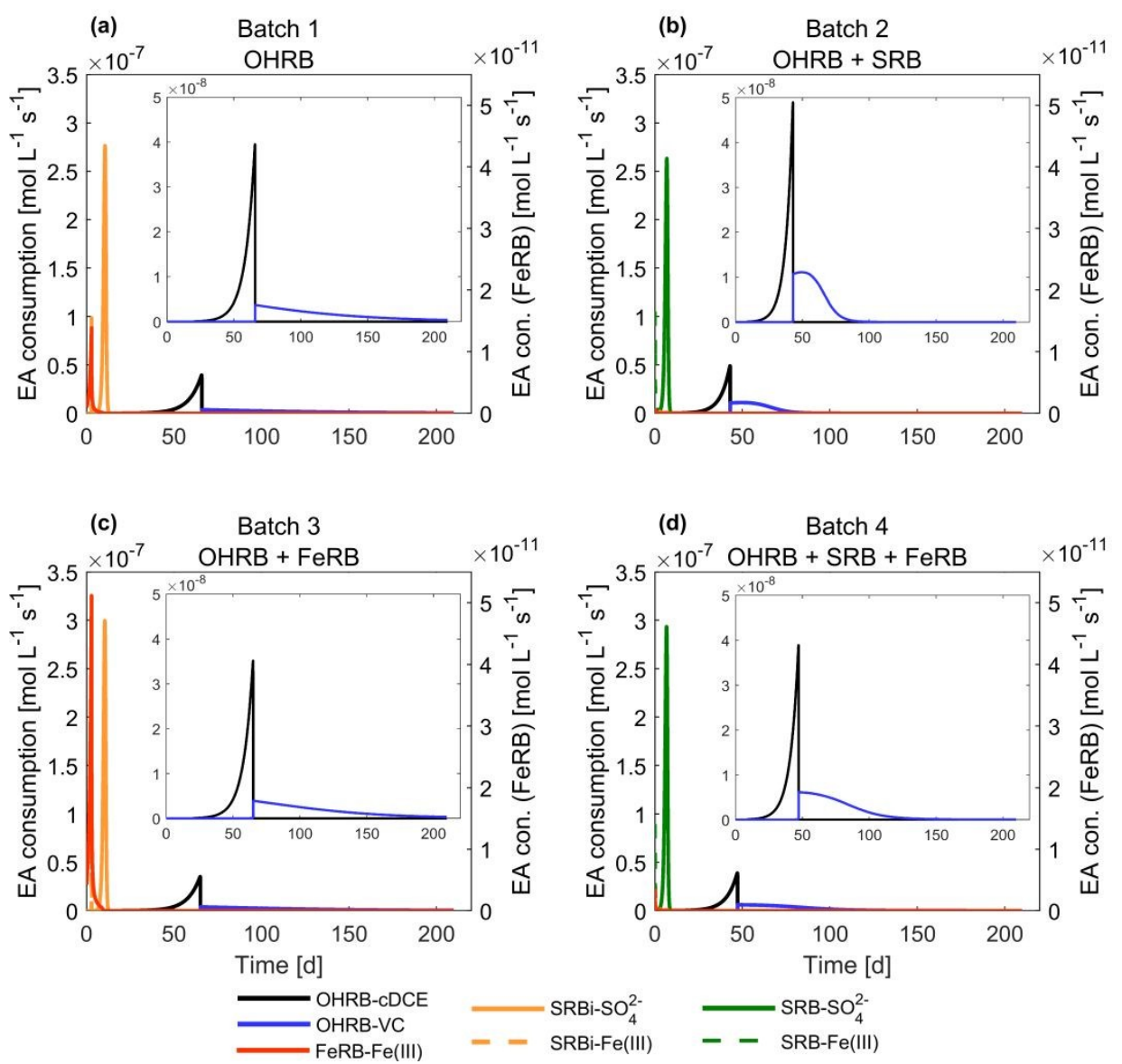

Figure 5. Simulated consumption rates for all microbial processes in each experimental batch.

Main panels include all microbial processes for each batch. Insert panels include only chlorinated ethene degradation processes for each batch. Note that Fe(III)-reduction by FeRB is displayed on the secondary $y$-axis. The OHRB consortium contains the endogenous FeRB and SRBi. Simulation results only; no data shown.

\subsection{Discussion}

The processes that support or inhibit $\mathrm{CDCE}$ and $\mathrm{VC}$ dechlorination are of particular importance from an applied environmental perspective, as in situ biodegradation of these compounds does not always reliably occur. These daughter compounds often accumulate in natural aquatic environments and may pose an even higher risk than the original contamination ${ }^{46}$. Batch experiments conducted 
with a Dehalococcoides-containing consortium capable of sequential dechlorination of $\mathrm{CDCE}$ to VC and ethene can shed light on the impact of other subsurface respiration guilds on these OHR processes. In order to obtain a fundamental understanding of the biogeochemical and mass transfer processes occurring in the system, multiple complementary datasets were collected and subsequently interpreted with a comprehensive modeling approach that includes degradation kinetics, aquatic chemistry, and interphase mass transfer.

Based on quantification of the maximum specific substrate utilization rates, $k_{\max , c D C E}$ and $k_{\max , V C}$, and the comparison of the $\mathrm{cDCE}$ and $\mathrm{VC}$ degradation rates (Figure 5), it appears that the primary effect of the addition of exogenous SRB is the stimulation of VC dechlorination. Addition of exogenous FeRB appears to have a slight stimulation effect on $\mathrm{VC}$ dechlorination and has a moderating effect when added in combination with exogenous SRB.

Sulfate reduction and $\mathrm{CDCE}$ dechlorination have been documented to proceed concurrently in a variety of systems, including batch experiments, flow-through experiments, and subsurface environments $14,32,47,48$. Concurrent cDCE dechlorination and sulfate reduction was not observed in the batches in this study; rather, cDCE dechlorination only began after an apparent lag phase of approximately one month, which coincided with the depletion of other electron acceptors in the medium. A lag phase of such length has not been observed with this consortium during regular cultivation and culture transfer, where these electron acceptors are not present in the medium. The stimulating effect on dechlorination caused by the exogenous SRB may be due to the rapid depletion of sulfate, and further stimulation may be seen with less sulfate in the medium. The converse may also be true, that the activity of the exogenous SRB stimulated dechlorination, and increased SRB activity would further stimulate the dechlorination by OHRB after recovery from the apparent lag phase. In a chemostat study conducted by Berggren et al., 2013 232 , the addition of sulfate to an OHRB-containing community resulted in decreased dechlorination kinetics of 

chlorinated ethenes by OHRB. The rate of VC dechlorination in particular decreased. This decrease correlated with a shift in abundance of strains of Dehalococcoides mccartyi present in the community. Because the abundance of strains cannot be distinguished with T-RFLP, it may be that, in the current study, sulfate-reduction spurs a shift in the Dehalococcoides sp. populations that can carry out chlorinated ethene reduction at different rates.

Iron reduction has been found to correlate with decreased VC dechlorination in field investigations ${ }^{8}$ and with decreased dechlorination of chlorinated ethenes in laboratory experiments ${ }^{49}$. In this study, the most pronounced effect from the addition of exogenous FeRB corresponds well with these findings; in Batches 2 and 4, the stimulating effect of exogenous SRB in Batch 4 is less than in Batch 2. In Batches 1 and 3, where the exogenous SRB are not present, additional FeRB have a slight stimulating effect on VC dechlorination. SRB and FeRB are functionally and phylogenetically diverse $29,50,51$, and it may be that the FeRB guild interacts with other populations (OHRB, SRB) differently depending upon the configuration of the microbial community. The FeRB may thus impact the OHRB in different ways.

Abiotic dechlorination of chlorinated ethenes has also been documented to occur, facilitated by iron-sulfide precipitates ${ }^{52,53}$. However, these reactions occur on a time-scale much greater than that of the experimental duration in the current study, and were not included in the conceptual and numerical models.

By using an electron acceptor limited system, community dynamics other than competition for electron donor may impact OHR. Many incomplete metabolic pathways have been identified in Dehalococcoides ${ }^{54}$, and the dependency of OHRB on other members of the microbial community is well-established ${ }^{15,55}$. The exogenous SRB may fulfill some such types of metabolic interdependency, for instance the added strain of Desulfovibrio vulgaris may synthesize a corrinoid 
cofactor that promotes faster dechlorination than the corrinoid provided in the growth medium ${ }^{56}$. It may also be the case that the endogenous SRB were present at a higher initial concentration than the SRBi, and thus could have a greater impact on the OHRB.

\section{Conclusion}

This study demonstrates that, even in a batch system, the dechlorination activity impacts and is in turn impacted by continuous feedback between microbial kinetics, aquatic chemistry, and mass transfer limitations. When all of these elements were taken into account, the effect of the community composition on the dechlorination rate was ascertained. Microbial communities that contained exogenous SRB performed cDCE and VC dechlorination at 129\% and 294\% faster rates, respectively, than the case where only endogenous SRB (SRBi) were present. Augmenting the community with additional FeRB stimulated VC dechlorination in presence of only SRBi, but moderated the stimulating effect of exogenous SRB. The different impacts from each SRB and FeRB guild member on the cDCE and VC dechlorination rates show that the dynamics within an OHRB-containing microbial community cannot always be accurately characterized by broad, categorical, inter-guild trends, but are rather the result of intricate interactions between individual community members.

\section{Conflict of interest}

There are no conflicts of interest to declare.

\section{Acknowledgements}

This study was funded by a DTU alliance PhD scholarship granted to Alexandra Murray. Massimo Rolle acknowledges the support of the Independent Research Fund Denmark (grant DFF-701700130). 


\section{References}

5011 C. Holliger, G. Wohlfarth and G. Diekert, FEMS Microbiol. Rev., 1999, 22, 383-398.

5066 D. E. Fennell and J. M. Gossett, Environ. Sci. Technol., 1998, 32, 2450-2460.

5077 Y. Yang and P. L. McCarty, Environ. Sci. Technol., 1998, 32, 3591-3597.

2 D. Henschler, Angew. Chem., Int. Ed., 1994, 33, 1920-1935.

3 P. M. Bradley, Bioremediat. J., 2003, 7, 81-109.

4 N. Shani, EPFL, 2012.

5 D. A. Fennell and J. M. Gossett, 1998.

8 N. Shani, P. Rossi and C. Holliger, Environ. Sci. Technol., 2013, 47, 6836-6845.

9 F. Malaguerra, J. C. Chambon, P. L. Bjerg, C. Scheutz and P. J. Binning, Environ. Sci. Technol., 2011, 45, 8395-8402.

10 F. Aulenta, M. Beccari, M. Majone, M. P. Papini and V. Tandoi, Process Biochem., 2008, 43, 161-168.

11 X. Mao, A. Polasko and L. Alvarez-Cohen, Appl. Environ. Microbiol., 2017, 83, 1-13.

12 L. Paul, S. Herrmann, C. Bender, J. Philips and E. Smolders, Water Res., 2013, 47, 25432554.

13 N. Wei and K. T. Finneran, Env. Sci Technol, 2011, 45, 7422-7430.

14 M. Harkness, A. Fisher, M. D. Lee, E. E. MacK, J. A. Payne, S. Dworatzek, J. Roberts, C. 

DOI:10.1186/1471-2164-13-327.

M. Duhamel, K. Mo and E. A. Edwards, Society, 2004, 70, 5538-5545.

S. Yu and L. Semprini, Biotechnol. Bioeng., 2004, 88, 451-464.

18 J. C. Chambon, P. L. Bjerg, C. Scheutz, J. Bælum, R. Jakobsen and P. J. Binning, Biotechnol. Bioeng., 2013, 110, 1-23.

19 I. Kouznetsova, X. Mao, C. Robinson, D. a. Barry, J. I. Gerhard and P. L. McCarty, $A d v$. Water Resour., 2010, 33, 969-986.

20 M. Thullner, M. Kampara, H. H. Richnow, H. Harms and L. Y. Wick, Environ. Sci. Technol., 2008, 42, 6544-6551.

21 C. Aeppli, M. Berg, O. A. Cirpka, C. Holliger, R. P. Schwarzenbach and T. B. Hofstetter, Environ. Sci. Technol., 2009, 43, 8813-8820.

B. Jin, S. B. Haderlein and M. Rolle, Environ. Sci. Technol., 2013, 47, 1443-1451.

K. Rouzeau-Szynalski, J. Maillard and C. Holliger, Appl. Microbiol. Biotechnol., 2011, 90, $361-368$.

24 J. F. Heidelberg, I. T. Paulsen, K. E. Nelson, E. J. Gaidos, W. C. Nelson, T. D. Read, J. a Eisen, R. Seshadri, N. Ward, B. Methe, R. a Clayton, T. Meyer, A. Tsapin, J. Scott, M. Beanan, L. Brinkac, S. Daugherty, R. T. DeBoy, R. J. Dodson, a S. Durkin, D. H. Haft, J. F. Kolonay, R. Madupu, J. D. Peterson, L. a Umayam, O. White, A. M. Wolf, J. Vamathevan, J. Weidman, M. Impraim, K. Lee, K. Berry, C. Lee, J. Mueller, H. Khouri, J. Gill, T. R. Utterback, L. a McDonald, T. V Feldblyum, H. O. Smith, J. C. Venter, K. H. Nealson and C. 
$540 \quad$ M. Fraser, Nat. Biotechnol., 2002, 20, 1118-1123.

54125 J. F. Heidelberg, R. Seshadri, S. A. Haveman, C. L. Hemme, I. T. Paulsen, J. F. Kolonay, J.

A. Eisen, N. Ward, B. Methe, L. M. Brinkac, S. C. Daugherty, R. T. Deboy, R. J. Dodson, A.

S. Durkin, R. Madupu, W. C. Nelson, S. A. Sullivan, D. Fouts, D. H. Haft, J. Selengut, J. D.

Peterson, T. M. Davidsen, N. Zafar, L. Zhou, D. Radune, G. Dimitrov, M. Hance, K. Tran,

H. Khouri, J. Gill, T. R. Utterback, T. V Feldblyum, J. D. Wall, G. Voordouw and C. M.

Fraser, Nat. Biotechnol., 2004, 22, 554-559.

Y. J. Tang, A. L. Meadows and J. D. Keasling, Biotechnol. Bioeng., 2007, 96, 125-133.

J. K. Fredrickson, M. F. Romine, A. S. Beliaev, J. M. Auchtung, M. E. Driscoll, T. S.

Gardner, K. H. Nealson, A. L. Osterman, G. Pinchuk, J. L. Reed, D. a Rodionov, J. L. M.

Rodrigues, D. a Saffarini, M. H. Serres, A. M. Spormann, I. B. Zhulin and J. M. Tiedje, Nat. Rev. Microbiol., 2008, 6, 592-603.

X. Tao, Y. Li, H. Huang, Y. Chen, P. Liu and X. Li, Ann. Microbiol., 2014, 64, 451-457.

D. A. Elias, J. M. Suflita, M. J. McInerney and L. R. Krumholz, Appl. Environ. Microbiol., 2004, 70, 413-420.

30 H. S. Park, S. Lin and G. Voordouw, Antonie van Leeuwenhoek, Int. J. Gen. Mol. Microbiol., 2008, 93, 79-85.

31 A. Murray, J. Maillard, B. Jin, M. Broholm, C. Holliger and M. Rolle, Water Res., 2019, 160, 484-496.

32 D. R. V Berggren, I. P. G. Marshall, M. F. Azizian, A. M. Spormann and L. Semprini, Environ. Sci. Technol., 2013, 47, 1879-1886. 
K. M. Ritalahti, B. K. Amos, Y. Sung, Q. Wu, S. S. Koenigsberg and F. E. Löffler, Appl. Environ. Microbiol., 2006, 72, 2765-2774.

E. Viollier, P. W. Inglett, K. Hunter, A. N. Roychoudhury and P. Van Cappellen, Appl. Geochemistry, 2000, 15, 785-790.

C. Zhou, Y. Zhou and B. E. Rittmann, Water Res., 2017, 119, 91-101.

G. F. Buttet, A. M. Murray, T. Goris, M. Burion, B. Jin, M. Rolle, C. Holliger and J. Maillard, FEMS Microbiol. Ecol., 2018, 94, 1-11.

S. R. Charlton and D. L. Parkhurst, Comput. Geosci., 2011, 37, 1653-1663.

M. Muniruzzaman and M. Rolle, Adv. Water Resour., 2016, 98, 1-15.

C. Liu, J. M. Zachara, Y. A. Gorby, J. E. Szecsody and C. F. Brown, Environ. Sci. Technol, 2001, 35, 1385-1393.

S. W. Poulton, M. D. Krom and R. Raiswell, Geochim. Cosmochim. Acta, 2004, 68, 37033715.

R. Jakobsen, Water Resour. Res., , DOI:10.1029/2006WR005663.

43 T. Kono, Biotechnol. Bioeng., 1968, 10, 105-131.

B. D. Wood, C. N. Dawson, J. E. Szecsody and G. P. Streile, Water Resour. Res., 1994, 30, $1833-1845$.

D. Buchner, B. Jin, K. Ebert, M. Rolle, M. Elsner and S. B. Haderlein, Environ. Sci. 
$581 \quad$ Technol., 2016, acs.est.6b03689.

58246 P. M. Bradley, Hydrogeol. J., 2000, 8, 104-111.

47 F. Aulenta, A. Pera, S. Rossetti, M. Petrangeli Papini and M. Majone, Water Res, 2007, 41, 27-38.

48 A. Badin, M. M. Broholm, C. S. Jacobsen, J. Palau, P. Dennis and D. Hunkeler, J. Contam. Hydrol., 2016, 192, 1-19.

49 L. Paul, R. Jakobsen, E. Smolders, H. J. Albrechtsen and P. L. Bjerg, Geomicrobiol. J., 2016, 33, 357-366.

50 Y. Men, H. Feil, N. C. Verberkmoes, M. B. Shah, D. R. Johnson, P. K. Lee, K. A. West, S. H. Zinder, G. L. Andersen and L. Alvarez-Cohen, ISME J, 2012, 6, 410-421.

51 K. A. Weber, L. A. Achenbach and J. D. Coates, Nat. Rev. Microbiol., 2006, 4, 752-764.

52 W. Lee and B. Batchelor, Environ. Sci. Technol., 2002, 36, 5147-5154.

53 T. L. Johnson, M. M. Scherer and P. G. Tratnyek, Environ. Sci. Technol., 1996, 30, 26342640.

54 M. A. Islam, E. A. Edwards and R. Mahadevan, PLoS Comput. Biol., , DOI:10.1371/journal.pcbi.1000887.

55 P. H. Wang, K. Correia, H. C. Ho, N. Venayak, K. Nemr, R. Flick, R. Mahadevan and E. A. Edwards, ISME J., , DOI:10.1038/s41396-018-0333-4.

56 J. Yan, B. Şimşir, A. T. Farmer, M. Bi, Y. Yang, S. R. Campagna and F. E. Löffler, ISME J., 2016, 10, 1092-1101. 


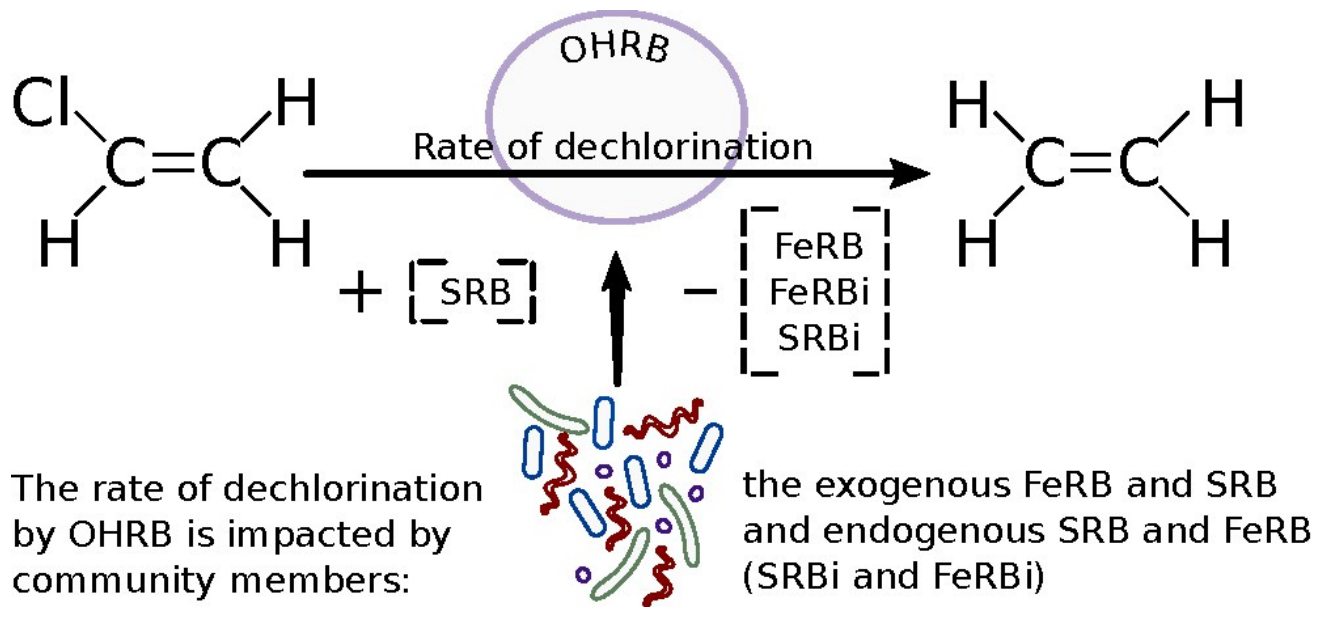

$126 \times 57 \mathrm{~mm}(200 \times 200$ DPI $)$ 